\title{
Driving south: a multi-gene phylogeny of the brown algal family Fucaceae reveals relationships and recent drivers of a marine radiation
}

\author{
Fernando G Cánovas*', Catarina F Mota, Ester A Serrão and Gareth A Pearson
}

\begin{abstract}
Background: Understanding the processes driving speciation in marine ecosystems remained a challenge until recently, due to the unclear nature of dispersal boundaries. However, recent evidence for marine adaptive radiations and ecological speciation, as well as previously undetected patterns of cryptic speciation is overturning this view. Here, we use multi-gene phylogenetics to infer the family-level evolutionary history of Fucaceae (intertidal brown algae of the northern Pacific and Atlantic) in order to investigate recent and unique patterns of radiative speciation in the genus Fucus in the Atlantic, in contrast with the mainly monospecific extant genera.

Results: We developed a set of markers from 13 protein coding genes based on polymorphic cDNA from EST libraries, which provided novel resolution allowing estimation of ancestral character states and a detailed reconstruction of the recent radiative history. Phylogenetic reconstructions yielded similar topologies and revealed four independent trans-Arctic colonization events by Fucaceae lineages, two of which also involved transitions from hermaphroditism to dioecy associated with Atlantic invasions. More recently, reversion of dioecious ancestral lineages towards hermaphroditism has occurred in the genus Fucus, particularly coinciding with colonization of more extreme habitats. Novel lineages in the genus Fucus were also revealed in association with southern habitats. These most recent speciation events occurred during the Pleistocene glaciations and coincided with a shift towards selfing mating systems, generally southward shifts in distribution, and invasion of novel habitats.

Conclusions: Diversification of the family occurred in the Late-Mid Miocene, with at least four independent transArtic lineage crossings coincident with two reproductive mode transitions. The genus Fucus arose in the Pliocene but radiated within a relatively short time frame about 2.5 million years ago. Current species distributions of Fucus suggest that climatic factors promoted differentiation between the two major clades, while the recent and rapid species radiation in the temperate clade during Pleistocene glacial cycles coincided with several potential speciation drivers.
\end{abstract}

\section{Background}

Most of the world's biodiversity occurs in the oceans, but understanding the processes that drive speciation in marine ecosystems remains a challenge particularly due to the perceived scarcity of geographical barriers to gene flow [1]. Although much marine diversity stems from climate-driven vicariant and colonization events [2,3], the accumulation of phylogenetic information is revealing that a considerable amount of diversity arises during adaptive radiations $[4,5]$, these periods of rapid

\footnotetext{
* Correspondence: fcgarcia@ualg.pt

CCMAR, CIMAR-Laboratório Associado, Universidade do Algarve, Gambelas 8005-139, Faro, Portugal
}

C) Biomed Central

(C) 2011 Cánovas et al; licensee BioMed Central Ltd. This is an Open Access article distributed under the terms of the Creative Commons Attribution License (http://creativecommons.org/licenses/by/2.0), which permits unrestricted use, distribution, and reproduction in any medium, provided the original work is properly cited. speciation associated with diversification into multiple
ecological niches (e.g., [6,7]), have also been shown to occur in marine systems where barriers to dispersal are not obvious [8].

Ecotypic divergence in response to strong environmental gradients or novel habitats (e.g., [8-11]) is a form of ecology-driven divergent selection that can cause population substructuring and differentiation [12]. Reproductive isolation occurs later, favouring assortative mating and facilitating speciation [13]. Mating system and reproductive ecology can also play an important role in marine speciation (e.g., [14]), although they remain under-studied in this environment. A major 
question is whether the evolution of hermaphroditic selfing entities from outcrossing lineages is a major trend in the sea, in common with terrestrial plant mating system evolution [15]. The evolutionary shift toward selfing increases colonization potential and reproductive assurance, while also serving to maintain local adaptations in stressful environments at the cost of genetic diversity and evolvability [16].

Geographical events driving speciation by vicariance or colonization have raised most interest in marine systems, and one of the most significant in the northern hemisphere was the opening of the Bering Strait. The formation of a marine connection between the North Pacific and the Arctic and North Atlantic Oceans $[17,18]$ allowed trans-oceanic dispersal and divergence between Pacific and Atlantic sister taxa (e.g., [19]). Although the Pliocene opening of the Bering Strait has been placed at ca. $5.5-5.4 \mathrm{Ma}$ [18], geomorphological and biological data [20] indicated that earlier openings possibly occurred in the Late Miocene. After the Pliocene opening, current patterns initially favoured Atlantic to Pacific exchanges [17] until ca. 3.5 Ma, after the closure of the Isthmus of Panama. The period of global cooling leading to the quaternary ice ages (starting ca. 1.8 Ma) began a series of oscillations in sea level and Arctic Ocean ice coverage, during which the Bering Strait closed and reopened at least six times [20]. Warmer periods coincided with higher trans-Arctic water flow, favouring inter-ocean dispersal events [21].

The brown algal family Fucaceae constitutes an important ecosystem-structuring component of cold to temperate intertidal communities in the North Pacific and North Atlantic Oceans. The wide northern hemisphere distribution of Fucaceae contrasts with their Australasian endemic sister families. This is thought to result from a trans-equatorial crossing with subsequent radiation in the northern hemisphere, a pattern paralleled in other families [22]. Ancestors of the Atlantic Fucaceae genera Ascophyllum, Pelvetia and Fucus, are hypothesized to have invaded the Atlantic through the Arctic during the last opening of the Bering Strait [23]. Fucus is the only Fucaceae genus that radiated extensively in the North Atlantic $[23,24]$. The cause of this process remains a challenging question that is only beginning to be understood $[11,25,26]$. Most extant genera within Fucaceae are, in strong contrast with Fucus, species-poor or monospecific. This allowed us to investigate which processes and events are associated with marine species radiations.

Speciation in Fucus may be associated with habitatspecificity (e.g., $[11,25,27])$ and variation in mating system and reproductive mode (e.g. [28-31]), with a biogeographic history shaped by glacial cycle-induced range shifts and secondary contact [26,32-36]. Although the phylogenetic history of the genus has never been fully reconstructed despite several attempts, two major clades were identified previously using nuclear [23] and mitochondrial DNA markers [24]. The first clade is northern, cold-water and relatively stress-susceptible (lineage 1 in [24]), and contains $F$. serratus and F. distichus (sensu lato [32]). The second clade (lineage 2) has a more southern extension with generally greater stress-tolerance, and contains F. ceranoides, F. vesiculosus, F. spiralis, F. guiryi, F. virsoides and F. radicans.

Our aim is to provide insight into marine speciation processes by inferring the phylogeny of the Fucaceae family. The study is particularly focused on unravelling the evolutionary history of radiative speciation within the genus Fucus, particularly the very speciose clade 2 (see below). In order to do this, we developed phylogenetic markers and used explicit biogeographic sampling of distinct populations and potentially novel species/entities suspected in clade 2 [11,25-27]. We also provide a temporal evolutionary hypothesis by calibrating the obtained phylogenies in geological time using the fossil record from extinct members of brown algae [37] and information from a dated brown algal multilocus phylogeny [38]. The phylogenetic framework is integrated with paleoreconstructions from the Earth's climatic history [39-41] and landmass trends from plate tectonic movements [42], to provide a hypothesis explaining the major historical events in the evolutionary history of Fucaceae.

\section{Results}

\section{Sequences and trees}

The dataset for the multi-gene phylogenetic analysis comprised 4878 aligned bp (1626 amino acids) stored in 13 partitions, each representing a different protein coding region (Additional file 1), based on the cDNA synthesized from isolated RNA from 84 individuals representing all genera in the Fucaceae.

The analyses yielded a well-defined phylogenetic hypothesis for the Fucaceae. Replicate runs of the Bayesian approach (see methods) converged onto similar posterior distributions after less than $5 \%$ of the $10^{6}$ generations. Phylogenetic reconstructions provided high confidence except for the branching of taxa $F$. radicans and F. gardneri. Relationships among Fucus species, with the exception of the most recently diverged entity $F$. radicans were resolved using this cDNA dataset.

\section{Genomic divergence at protein-coding loci}

Analysis of the 13 partial coding sequences provided 395 variable sites, 31 of which were identified as singletons (see Additional file 2 for accession numbers). Intra-specific nucleotide (nt) variability in the genomic data set was low, ranging from zero to 10 single nucleotide polymorphisms (SNP) in the most diverse species, Pelvetiopsis limitata (Table 1). Intra-specific diversity, measured 
Table 1 Genomic data estimations

\begin{tabular}{|c|c|c|c|c|c|c|c|c|c|c|c|c|c|c|c|c|}
\hline & \multirow[b]{2}{*}{ Species } & \multicolumn{3}{|c|}{ Fucus clade 1} & \multirow[b]{2}{*}{$\begin{array}{c}F . \\
\text { radicans }\end{array}$} & \multicolumn{5}{|c|}{ Fucus clade 2} & \multirow[b]{2}{*}{$\begin{array}{c}F . \\
\text { vesiculosus } \\
\text { Southern }\end{array}$} & \multirow[b]{2}{*}{$\underset{\text { californicus }}{\text { H. }}$} & \multirow[b]{2}{*}{$\begin{array}{c}\text { P. } \\
\text { canaliculata }\end{array}$} & \multirow[b]{2}{*}{$\begin{array}{c}P . \\
\text { limitata }\end{array}$} & \multirow[b]{2}{*}{$\begin{array}{c}\text { S. } \\
\text { compressa }\end{array}$} & \multirow[b]{2}{*}{$\begin{array}{c}A . \\
\text { nodosum }\end{array}$} \\
\hline & & $\begin{array}{c}F . \\
\text { serratus }\end{array}$ & $\begin{array}{c}F . \\
\text { evanescens }\end{array}$ & $\begin{array}{c}F . \\
\text { gardneri }\end{array}$ & & $\begin{array}{c}F . \\
\text { ceranoides }\end{array}$ & $\begin{array}{c}\text { F. } \\
\text { spiralis }\end{array}$ & $\begin{array}{c}F . \\
\text { guiryi }\end{array}$ & $\begin{array}{c}F . \\
\text { virsoides }\end{array}$ & $\begin{array}{c}F . \\
\text { vesiculosus } \\
\text { Northern }\end{array}$ & & & & & & \\
\hline & F. serratus & 2.56 & $\begin{array}{c}0.004 \pm \\
0.001\end{array}$ & $\begin{array}{c}0.004 \pm \\
0.001\end{array}$ & $\begin{array}{c}0.006 \pm \\
0.001\end{array}$ & $\begin{array}{l}0.007 \pm \\
0.002\end{array}$ & $\begin{array}{c}0.006 \\
\pm \\
0.001\end{array}$ & $\begin{array}{c}0.007 \\
\pm \\
0.001\end{array}$ & $\begin{array}{l}0.008 \pm \\
0.002\end{array}$ & $\begin{array}{c}0.006 \pm \\
0.001\end{array}$ & $\begin{array}{c}0.006 \pm \\
0.001\end{array}$ & $\begin{array}{l}0.014 \pm \\
0.003\end{array}$ & $\begin{array}{c}0.026 \pm \\
0.004\end{array}$ & $\begin{array}{l}0.014 \pm \\
0.003\end{array}$ & $\begin{array}{l}0.027 \pm \\
0.005\end{array}$ & $\begin{array}{c}0.026 \pm \\
0.004\end{array}$ \\
\hline \multirow[t]{4}{*}{$\begin{array}{l}\text { Fucus } \\
\text { lineage } \\
1\end{array}$} & $\begin{array}{c}F . \\
\text { evanescens }\end{array}$ & 0.35 & 2.67 & $\begin{array}{l}0.001 \pm \\
0.000\end{array}$ & $\begin{array}{l}0.007 \pm \\
0.002\end{array}$ & $\begin{array}{l}0.008 \pm \\
0.002\end{array}$ & $\begin{array}{c}0.007 \\
\pm \\
0.002\end{array}$ & $\begin{array}{c}0.007 \\
\pm \\
0.002\end{array}$ & $\begin{array}{l}0.009 \pm \\
0.002\end{array}$ & $\begin{array}{l}0.007 \pm \\
0.002\end{array}$ & $\begin{array}{l}0.007 \pm \\
0.002\end{array}$ & $\begin{array}{l}0.015 \pm \\
0.003\end{array}$ & $\begin{array}{l}0.027 \pm \\
0.005\end{array}$ & $\begin{array}{l}0.015 \pm \\
0.003\end{array}$ & $\begin{array}{l}0.028 \pm \\
0.005\end{array}$ & $\begin{array}{l}0.027 \pm \\
0.005\end{array}$ \\
\hline & F. gardneri & 0.38 & 0.09 & 0.00 & $\begin{array}{l}0.007 \pm \\
0.002\end{array}$ & $\begin{array}{l}0.008 \pm \\
0.002\end{array}$ & $\begin{array}{c}0.007 \\
\pm \\
0.002\end{array}$ & $\begin{array}{c}0.008 \\
\pm \\
0.002\end{array}$ & $\begin{array}{l}0.009 \pm \\
0.002\end{array}$ & $\begin{array}{l}0.008 \pm \\
0.002\end{array}$ & $\begin{array}{l}0.008 \pm \\
0.002\end{array}$ & $\begin{array}{l}0.016 \pm \\
0.003\end{array}$ & $\begin{array}{l}0.027 \pm \\
0.005\end{array}$ & $\begin{array}{l}0.015 \pm \\
0.003\end{array}$ & $\begin{array}{l}0.029 \pm \\
0.005\end{array}$ & $\begin{array}{l}0.027 \pm \\
0.005\end{array}$ \\
\hline & F. radicans & 0.61 & 0.68 & 0.72 & 0.00 & $\begin{array}{l}0.002 \pm \\
0.001\end{array}$ & $\begin{array}{c}0.000 \\
\pm \\
0.000\end{array}$ & $\begin{array}{c}0.000 \\
\pm \\
0.000\end{array}$ & $\begin{array}{c}0.002 \pm \\
0.001\end{array}$ & $\begin{array}{c}0.000 \pm \\
0.000\end{array}$ & $\begin{array}{c}0.000 \pm \\
0.000\end{array}$ & $\begin{array}{l}0.014 \pm \\
0.003\end{array}$ & $\begin{array}{l}0.024 \pm \\
0.004\end{array}$ & $\begin{array}{l}0.013 \pm \\
0.003\end{array}$ & $\begin{array}{l}0.025 \pm \\
0.005\end{array}$ & $\begin{array}{c}0.025 \pm \\
0.004\end{array}$ \\
\hline & $\begin{array}{c}F . \\
\text { ceranoides }\end{array}$ & 0.67 & 0.75 & 0.79 & 0.22 & 2.67 & $\begin{array}{c}0.002 \\
\pm \\
0.001\end{array}$ & $\begin{array}{c}0.003 \\
\pm \\
0.001\end{array}$ & $\begin{array}{c}0.004 \pm \\
0.001\end{array}$ & $\begin{array}{c}0.002 \pm \\
0.001\end{array}$ & $\begin{array}{c}0.002 \pm \\
0.001\end{array}$ & $\begin{array}{l}0.014 \pm \\
0.003\end{array}$ & $\begin{array}{l}0.025 \pm \\
0.004\end{array}$ & $\begin{array}{l}0.013 \pm \\
0.003\end{array}$ & $\begin{array}{c}0.026 \pm \\
0.004\end{array}$ & $\begin{array}{c}0.025 \pm \\
0.004\end{array}$ \\
\hline \multirow[t]{9}{*}{$\begin{array}{l}\text { Fucus } \\
\text { lineage } \\
2\end{array}$} & F. spiralis & 0.61 & 0.69 & 0.72 & 0 & 0.22 & 0.44 & $\begin{array}{c}0.000 \\
\pm \\
0.000\end{array}$ & $\begin{array}{c}0.002 \pm \\
0.001\end{array}$ & $\begin{array}{c}0.000 \pm \\
0.000\end{array}$ & $\begin{array}{c}0.000 \pm \\
0.000\end{array}$ & $\begin{array}{l}0.014 \pm \\
0.003\end{array}$ & $\begin{array}{l}0.024 \pm \\
0.004\end{array}$ & $\begin{array}{l}0.013 \pm \\
0.003\end{array}$ & $\begin{array}{l}0.025 \pm \\
0.005\end{array}$ & $\begin{array}{c}0.025 \pm \\
0.004\end{array}$ \\
\hline & F. guiryi & 0.64 & 0.71 & 0.75 & 0.03 & 0.25 & 0.04 & 1.27 & $\begin{array}{c}0.002 \pm \\
0.001\end{array}$ & $\begin{array}{c}0.000 \pm \\
0.000\end{array}$ & $\begin{array}{c}0.000 \pm \\
0.000\end{array}$ & $\begin{array}{l}0.014 \pm \\
0.003\end{array}$ & $\begin{array}{c}0.025 \pm \\
0.004\end{array}$ & $\begin{array}{c}0.013 \pm \\
0.003\end{array}$ & $\begin{array}{c}0.026 \pm \\
0.005\end{array}$ & $\begin{array}{c}0.025 \pm \\
0.004\end{array}$ \\
\hline & F. virsoides & 0.78 & 0.86 & 0.9 & 0.18 & 0.4 & 0.18 & 0.21 & 2.00 & $\begin{array}{c}0.002 \pm \\
0.001\end{array}$ & $\begin{array}{l}0.002 \pm \\
0.001\end{array}$ & $\begin{array}{l}0.015 \pm \\
0.003\end{array}$ & $\begin{array}{c}0.026 \pm \\
0.004\end{array}$ & $\begin{array}{l}0.015 \pm \\
0.003\end{array}$ & $\begin{array}{l}0.027 \pm \\
0.005\end{array}$ & $\begin{array}{l}0.027 \pm \\
0.005\end{array}$ \\
\hline & $\begin{array}{c}F . \\
\text { vesiculosus } \\
\text { Northern }\end{array}$ & 0.62 & 0.69 & 0.73 & 0.01 & 0.23 & 0.02 & 0.04 & 0.19 & 0.78 & $\begin{array}{c}0.000 \pm \\
0.000\end{array}$ & $\begin{array}{l}0.014 \pm \\
0.003\end{array}$ & $\begin{array}{l}0.024 \pm \\
0.004\end{array}$ & $\begin{array}{l}0.013 \pm \\
0.003\end{array}$ & $\begin{array}{c}0.026 \pm \\
0.004\end{array}$ & $\begin{array}{c}0.025 \pm \\
0.004\end{array}$ \\
\hline & $\begin{array}{c}F . \\
\text { vesiculosus } \\
\text { Southern }\end{array}$ & 0.61 & 0.69 & 0.73 & 0.01 & 0.23 & 0.01 & 0.04 & 0.19 & 0.02 & 0.78 & $\begin{array}{l}0.014 \pm \\
0.004\end{array}$ & $\begin{array}{l}0.024 \pm \\
0.005\end{array}$ & $\begin{array}{l}0.013 \pm \\
0.004\end{array}$ & $\begin{array}{l}0.025 \pm \\
0.005\end{array}$ & $\begin{array}{l}0.025 \pm \\
0.005\end{array}$ \\
\hline & $\begin{array}{c}H . \\
\text { californicus }\end{array}$ & 1.38 & 1.46 & 1.49 & 1.31 & 1.33 & 1.31 & 1.34 & 1.48 & 1.32 & 1.31 & 7.33 & $\begin{array}{c}0.025 \pm \\
0.004\end{array}$ & $\begin{array}{l}0.008 \pm \\
0.002\end{array}$ & $\begin{array}{l}0.027 \pm \\
0.005\end{array}$ & $\begin{array}{c}0.025 \pm \\
0.004\end{array}$ \\
\hline & $\begin{array}{c}P . \\
\text { canaliculata }\end{array}$ & 2.47 & 2.55 & 2.58 & 2.32 & 2.34 & 2.32 & 2.35 & 2.49 & 2.33 & 2.32 & 2.41 & 0.00 & $\begin{array}{c}0.024 \pm \\
0.004\end{array}$ & $\begin{array}{l}0.027 \pm \\
0.005\end{array}$ & $\begin{array}{c}0.025 \pm \\
0.004\end{array}$ \\
\hline & P. limitata & 1.34 & 1.41 & 1.45 & 1.22 & 1.25 & 1.23 & 1.25 & 1.40 & 1.23 & 1.23 & 0.74 & 2.25 & 14.67 & $\begin{array}{l}0.024 \pm \\
0.004\end{array}$ & $\begin{array}{c}0.023 \pm \\
0.004\end{array}$ \\
\hline & $\begin{array}{c}\text { S. } \\
\text { compressa }\end{array}$ & 2.57 & 2.69 & 2.72 & 2.41 & 2.44 & 2.42 & 2.44 & 2.59 & 2.42 & 2.42 & 2.60 & 2.54 & 2.30 & 0.67 & $\begin{array}{l}0.014 \pm \\
0.003\end{array}$ \\
\hline
\end{tabular}

Number of base substitutions per site and standard error (1000 bootstraps) calculated using the maximum composite likelihood method ([92] provided in MEGA v4.1 [93]; above diagonal) and percentage of divergence based on average number of differences (below diagonal) between species. Divergence levels lower than $1 \%$ as well as zero substitutions are emphasized. Diagonal elements: number of pairwise differences within species. 
as the average number of nucleotide differences between pairwise sequences across all loci (Table 1), revealed two significantly more diverse species: P. limitata (14.67) and Hesperophycus californicus (7.33). All the other species showed average values below 3 nucleotide differences.

The highest inter-species differentiation was seen between the genus Fucus and all the other Fucaceae, ranging from $1.58 \%$ to a maximum of $3.05 \%$ ( 0.013 to 0.027 average number of substitutions per site). The lowest differentiation between genera was that between H. californicus and P. limitata $(0.87 \%$ and $0.008 \pm 0.002$ average number of substitutions per site), which is close to values found between species of the two major Fucus clades (less than $0.8 \%$ and $0.008 \pm 0.002$ ). The heat shock 90 family protein-coding gene had a 3-codon insertion in Silvetia compressa that clearly differentiated this species, despite it displaying low genetic differentiation from a sister genus, here A. nodosum (1.5\%).

\section{Multi-gene phylogeny of the family Fucaceae}

Both maximum likelihood and Bayesian-based reconstruction algorithms yielded similar topologies (Figure 1 ), differing mostly in the branch lengths and support values. All current species were resolved except the recent Baltic species F. radicans, and all nodes that split different species showed high support for both algorithms. Phylogenies built using cDNA nucleotide sequences therefore resulted in much improved resolution over previously used markers, despite lower genetic distances than earlier described with ITS. Re-analysis of ITS data [23] confidently inferred the Ascophyllum - Silvetia clade to root the remaining divergence events in the Fucaceae using the $13 \mathrm{cDNA}$ loci.

The 13 protein-coding genes identified the same two major clades within Fucus as ITS ([23] and reanalyzed data in Additional file 3) and mitochondrial DNA [24]. In Fucus clade 1, two subclades were again recovered. Dioecious $F$. serratus and the hermaphroditic group corresponding to $F$. distichus sensu lato, in which our sampling of the geographic extremes revealed low intraspecific divergence.

In contrast with the polytomy found previously $[23,24]$, species relationships within clade 2 were resolved (Figure 1), with the exception of $F$. radicans (see below). The earliest diverging lineage leads to the estuarine species $F$. ceranoides. This is followed by the discovery that $F$. vesiculosus is not monophyletic, but is split according to geographical location of the samples into a northern (splitting earlier from the remaining species; Figure 1, ML phylogeny), and a southern clade. The latter shares a common ancestor with the hermaphroditic species in this lineage. The southern $F$. vesiculosus samples appear to form two distinct clades of geographically similar individuals (Figure 1, Bayesian phylogeny) but they are grouped in a single clade in the Bayesian inferences based on the coalescent and Yule speciation models (Figure 2 and Additional file 4). The recently derived species $F$. radicans was not resolved and grouped with sympatric northern $F$. vesiculosus. All of these dioecious species/entities were basal to the clade containing the three hermaphroditic species, the Mediterranean endemic $F$. virsoides branching first, followed by the clade containing F. spiralis and the recently described southern species $F$. guiryi [11], that was clearly differentiated from $F$. spiralis with high node values for both algorithms. Phylogenetic trees in Figure 1 were built after excluding $F$. guiryi individuals from the introgressed contact range (see discussion). The resulting trees including those individuals (shown in Additional file 5) show the effects of introgressed individuals in confounding the inference of vertical lineage splitting [11].

\section{Evolutionary rates and molecular dating}

Bayesian MCMC inference resulted in an estimate of the mean evolutionary rate across Fucaceae of 0.0016 substitutions per thousand years (95\% confidence interval 0.0008 to 0.0025 ). We emphasize that, taking into account the confidence intervals, the evolutionary rates for the separate coding genes largely overlapped and the coefficient of variation across the tree was 0.6 . The nucleotide substitutions per site range from values close to zero for comparisons within Fucus spp. up to $0.029 \pm 0.005$ for the whole family (S. compressa and F. gardneri; Table 1).

Coalescent theory and the Yule speciation model were used to evaluate the history of Fucaceae (Figure 2). Trees agree well with Bayesian and ML phylogenetic reconstructions (Figure 1). Both demographic models broadly coincided when used to infer dates for the nodes placed near the origin of all Fucaceae genera, but differed considerably in dating recent speciation events, particularly within Fucus. The time intervals reported are maximally conservative and correspond to the range for both demographic models together. Our molecular dating leads to an estimate for the origin of the diversification of Fucaceae around 19.5-7.0 million years ago (Ma) (Figure 2 and Additional file 6). The origin of the lineage leading to Pelvetia canaliculata, eventually resulting in an Atlantic invasion, was dated at 16.4 to 5.4 Ma. Divergence between the lineages leading to Ascophyllum nodosum and to the genus Silvetia (11.7 to $1 \mathrm{Ma}$ ) was coincident in time with the split of the lineage leading to $H$. californicus and P. limitata from the Fucus genus lineage (12.2 to $2.7 \mathrm{Ma})$. Both of these splits correspond to a Pacific-Atlantic crossing by members of the lineages now represented by the genera $A s c 0$ phyllum and Fucus in the Atlantic. The diversification of 


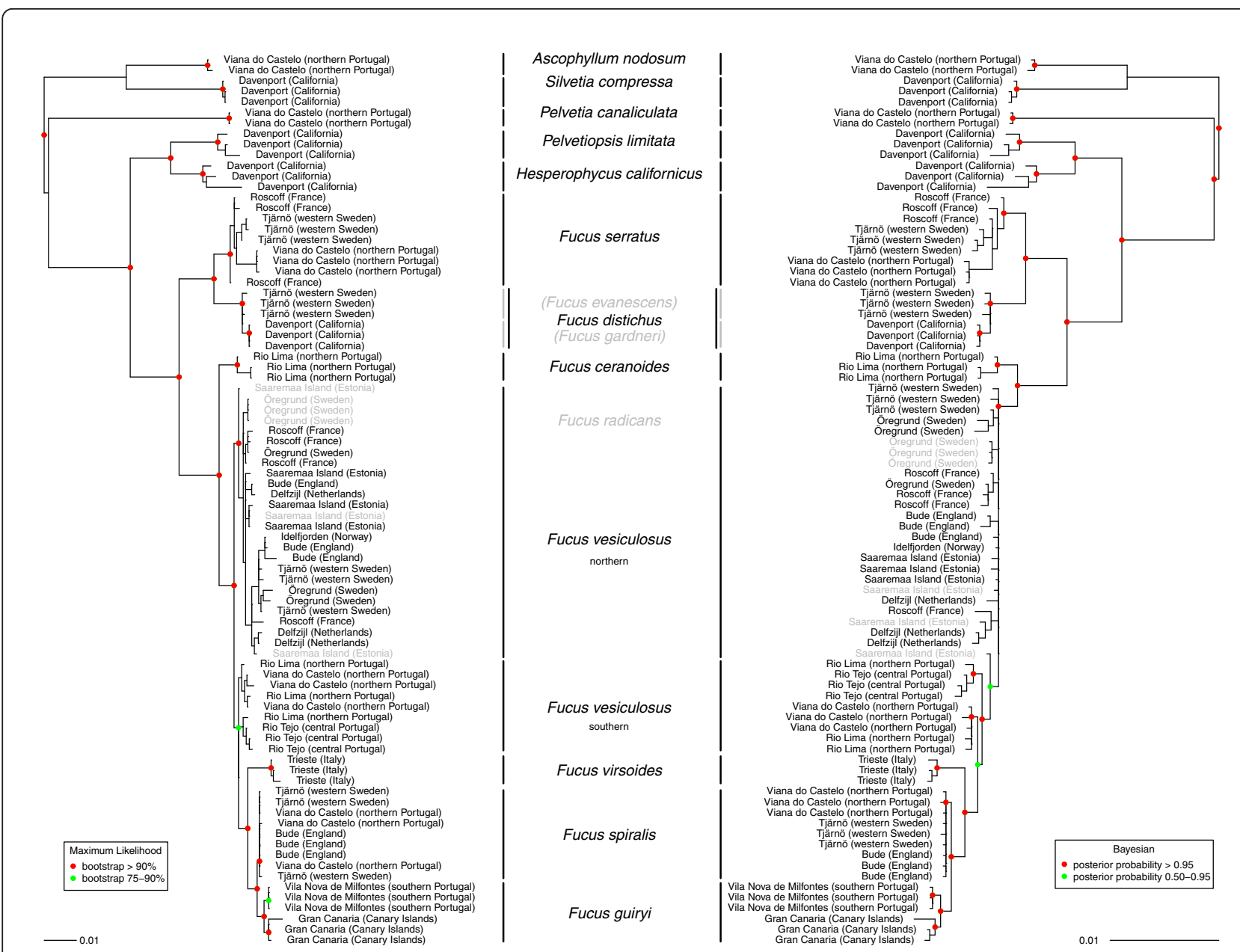

Figure 1 Multi-gene phylogenetic reconstruction from 13 cDNA loci. Multi-gene phylogenetic reconstructions using 13 nuclear transcriptomic regions. Shown are the 50\% majority rule consensus tree of maximum likelihood bootstraps (left) and the 50\% majority rule percentage of support for clades given by Bayesian posterior probabilities from one million generation MCMC analysis (right). CDNA trees were rooted using as outgroup the most basal genera, Ascophyllum and Silvetia, determined as basal according to phylogenetic re-analysis of Fucaceae ITS data using its sister families as outgroup [23] (see details in Methods section for the analyses performed based on [23] and Additional file 2 for the corresponding phylogenetic reconstruction).

the genus Fucus into two clades was estimated at 9.5 to 1.6 Ma. All the predicted speciation events within each Fucus clade were placed within the last 3.8 million years (Myr).

\section{Tests of mating system evolutionary hypotheses}

The best fitting model for the different diversification hypotheses related to the evolution of mating systems (see Table 2 and estimation of ancestral character states and diversification in the Methods section) was the oneparameter Markov k-state model $($ MK1; AIC $=104.522)$. This model indicates that speciation $(\lambda)$ and extinction $(\mu)$ rates were state-independent $\lambda_{\text {dioecious }}=\lambda_{\text {hermaphroditic }}$ $\left.=0.24 ; \mu_{\text {dioecious }}=\lambda_{\text {hermaphroditic }}=0.14\right)$ and that the transition between character states was also bidirectional and state-independent $(q 01=q 10=0.56)$. Ancestral state reconstruction from the scaled likelihood of every state of the character (Figure 3) resulted in poor resolution of deeper nodes, showing equal likelihood for either character state (dioecious vs. hermaphroditic). The node describing the state of the mrca of all Fucus species showed higher scaled likelihood for the state of dioecy $\left(\operatorname{logLik_{\text {scaled}}}=0.63\right)$, as well as the other nodes involved in the evolution of the genus $\left(\log L i k_{\text {scaled }}\right.$ ranged from 0.54 to 0.84 ). However the two more recent ancestors of $F$. virsoides, $F$. spiralis and F. guiryi were estimated to have been hermaphroditic $\left(\operatorname{logLi} k_{\text {scaled }}=0.92\right.$ and 0.99 , respectively). The common ancestor of Hesperophycus and Pelvetiopsis was also estimated as having been hermaphroditic $\left(\operatorname{logLi} k_{\text {scaled }}=0.62\right)$. 


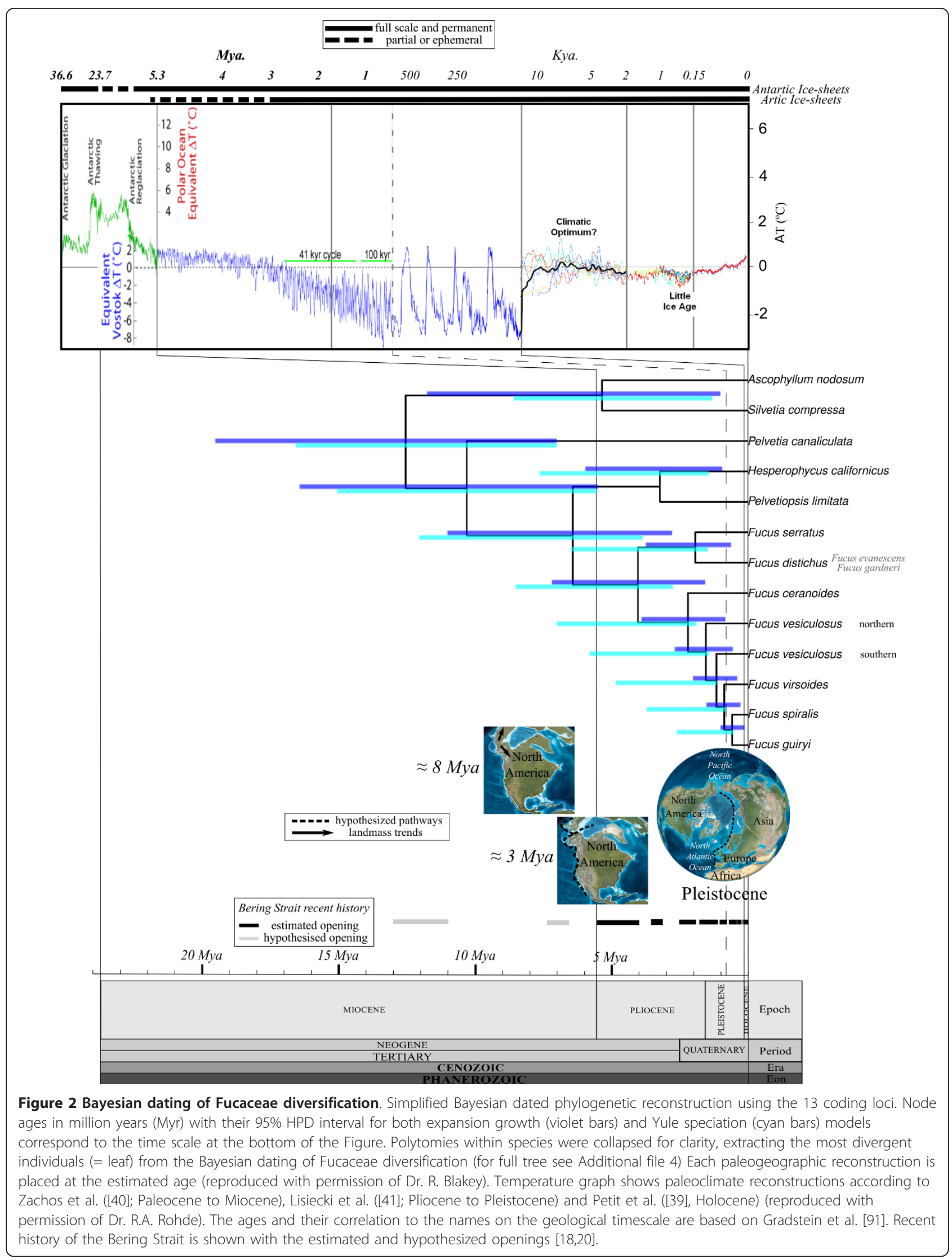


Table 2 Tests of mating system evolution hypotheses

\begin{tabular}{|c|c|c|c|c|c|c|c|c|c|c|}
\hline Scenario & Df & $\lambda 0$ & $\lambda 1$ & $\mu 0$ & $\mu 1$ & 901 & $q 10$ & logLik & $A I C$ & $P$ \\
\hline Asymmetric parameters & 6 & 0.000 & 0.289 & 0.398 & 0.000 & 0.441 & 0.524 & -48.299 & 108.597 & \\
\hline Asymmetric speciation & 4 & 0.000 & 0.350 & \multicolumn{2}{|c|}{$\mu 1 \sim \mu 0$} & \multicolumn{2}{|c|}{$q 01 \sim q 10$} & -48.519 & 105.040 & \\
\hline Asymmetric extinction & 4 & \multicolumn{2}{|c|}{$\lambda 1 \sim \lambda 0$} & 0.364 & 0.000 & \multicolumn{2}{|c|}{$q 01 \sim q 10$} & -48.997 & 106.000 & . \\
\hline Source (dioecious)-sink system & 4 & \multicolumn{2}{|c|}{$\lambda 1 \sim \lambda 0$} & \multicolumn{2}{|c|}{$\mu 1 \sim \mu 0$} & 0.086 & - & -54.358 & 114.720 & * \\
\hline Source (hermaphoditic)-sink system & 4 & \multicolumn{2}{|c|}{$\lambda 1 \sim \lambda 0$} & \multicolumn{2}{|c|}{$\mu 1 \sim \mu 0$} & - & 0.073 & -52.686 & 111.370 & ** \\
\hline Symmetric parameters (MK1) & 3 & \multicolumn{2}{|c|}{$\lambda 1 \sim \lambda 0$} & \multicolumn{2}{|c|}{$\mu 1 \sim \mu 0$} & \multicolumn{2}{|c|}{$901 \sim q 10$} & -49.261 & 104.522 & . \\
\hline Sink-sink system (MK2) & 4 & \multicolumn{2}{|c|}{$\lambda 1 \sim \lambda 0$} & \multicolumn{2}{|c|}{$\mu 1 \sim \mu 0$} & 0.758 & 0.538 & -49.068 & 106.135 & \\
\hline
\end{tabular}

Speciation $(\lambda)$, extinction $(\mu)$ and transition $(q)$ rates between the two states of the mating system character $(0$, dioecious; 1 , hermaphroditic). Complete asymmetric model and different scenarios of state-independent and state-dependent diversification (rates constrained to be equal), and unidirectional and bidirectional transitions were tested: 1) asymmetric model; 2) asymmetric speciation or state-independent extinction and transition rates; 3 ) asymmetric extinction or state-independent speciation and transition rates; 4) Source (dioecious)- sink system or state-independent diversification rates and transition from hermaphroditic to dioecious state constrained to $0 ; 5)$ Source (hermaphroditic)- sink system or state-independent diversification rates and transition from dioecious to hermaphroditic state constrained to 0 ; 6) symmetric parameters or MK1 model; 7) Sink-sink system or MK2 model [81-84,86]. Log-likelihood, Akaike information criteria (AIC) and log-likelihood ratio test $(\mathrm{P})$ are also provided for comparison between models.

Tests of geographic hypotheses related to the Bering Strait oceanic boundary

The testing of hypotheses related to geographic (i.e., Pacific vs. Atlantic/Arctic) origin and diversification (see Table 3 and estimation of ancestral character states and diversification from the Methods section) showed the GeoSSE model as having the best fit $(A I C=107.66$, loglikelihood $=-46.83)$. The model indicates that diversification rates were state-dependent $\left(s_{\text {Pacific }}=0.195 ; s_{\text {Atlan- }}\right.$ tic $\left.=0.019 ; x_{\text {Pacific }}=0.049 ; x_{\text {Atlantic }}=0.000\right)$, and that the dispersal rates between the two geographic regions (both sides of the Bering Strait) were almost unidirectional from the Pacific $\left(d_{\text {Pacific to Atlantic }}=0.075\right)$. The DEC model also reported low dispersal (0.032) and extinction (0.000) rates (log.likelihood $=-13.25$ ). Ancestral state reconstruction was also performed for the sink-sink GeoSSE model (second best model like MK2) and DEC models (Figure $4 \mathrm{a}$ and $4 \mathrm{~b}$, respectively). Deeper nodes were poorly resolved by the sink-sink model, showing similar scaled likelihoods for either character state (Pacific vs. Atlantic; Figure 4a), but DEC provided better estimates for the alternative scenarios (branches in Figure 4b). Estimates of the geographic origin of the family were similar for Pacific and Atlantic Oceans using the GeoSSE model (logLik $k_{\text {scaled }}=0.42$ and 0.58, respectively), while the DEC model placed the origin in the Pacific $\left(\operatorname{logLi} k_{\text {scaled }}=0.47\right)$ or in both biogeographic areas across the Bering Strait $\left(\log L i k_{\text {scaled }}=0.32\right.$; pie on nodes in Figure 4b). This last observation agrees with the rate of between-region mode of speciation obtained by the GeoSSE model $\left(s_{\text {Pacific-Atlantic }}=1.225\right)$ that was higher than within-region speciation rates. Alternatively, these results also agree with hypothetical divergence along the boundary between both regions in the Arctic Ocean. The most recent common ancestor to Fucus was estimated as Atlantic $\left(\operatorname{logLi} k_{\text {scaled }}=0.86\right.$ and 0.63 for both GeoSSE and DEC models, respectively). Finally, both models predicted an Atlantic ancestor of $F$. serratus and $F$. distichus (clade $1 ; \log L i k_{\text {scaled }}=0.70$ for the nodes and 0.53 for the inheritance scenario).

\section{Discussion}

A multi-gene phylogenetic approach resulted in a much finer resolution of relationships at the tips of the tree compared with previous phylogenies. This framework allowed the estimation of dates of divergence and patterns of speciation across the family and within the recently radiated genus Fucus.

\section{Dating inter-ocean divergence events in Fucaceae}

The models used returned similar dated intervals on deeper nodes corresponding to the splitting events of ancestral Fucaceae lineages, but were less congruent in dating recent speciation events. This is likely due to the constraints of the priors used $[43,44]$. Although we remain conservative by reporting the range for both models, the narrower and more recent coalescent-based intervals at the tips of the tree are more in agreement with the biological processes associated with speciation in these taxa [45].

The most likely origin of the Fucaceae is in the Pacific Ocean during the mid to late Miocene (19.5-7.0 Ma, estimated based on 23-7 Ma from [37] and 19.4-8.0 Ma from ITS; see Additional file 6), when an ancestor of the Fucaceae might have been able to colonize the North Pacific, splitting from the Australasian sister lineages Xiphophoraceae and Hormosiraceae [23,38]. Despite support for both alternative hypotheses for the Fucaceae geographic origin, a Pacific origin involves a more direct route from the southern (Australasia) to the northern Pacific (and is supported by diversification rates and the DEC model), whereas the alternative hypothesis of an Atlantic origin requires a more complex dispersal path. A Pacific origin is also consistent with the northward 


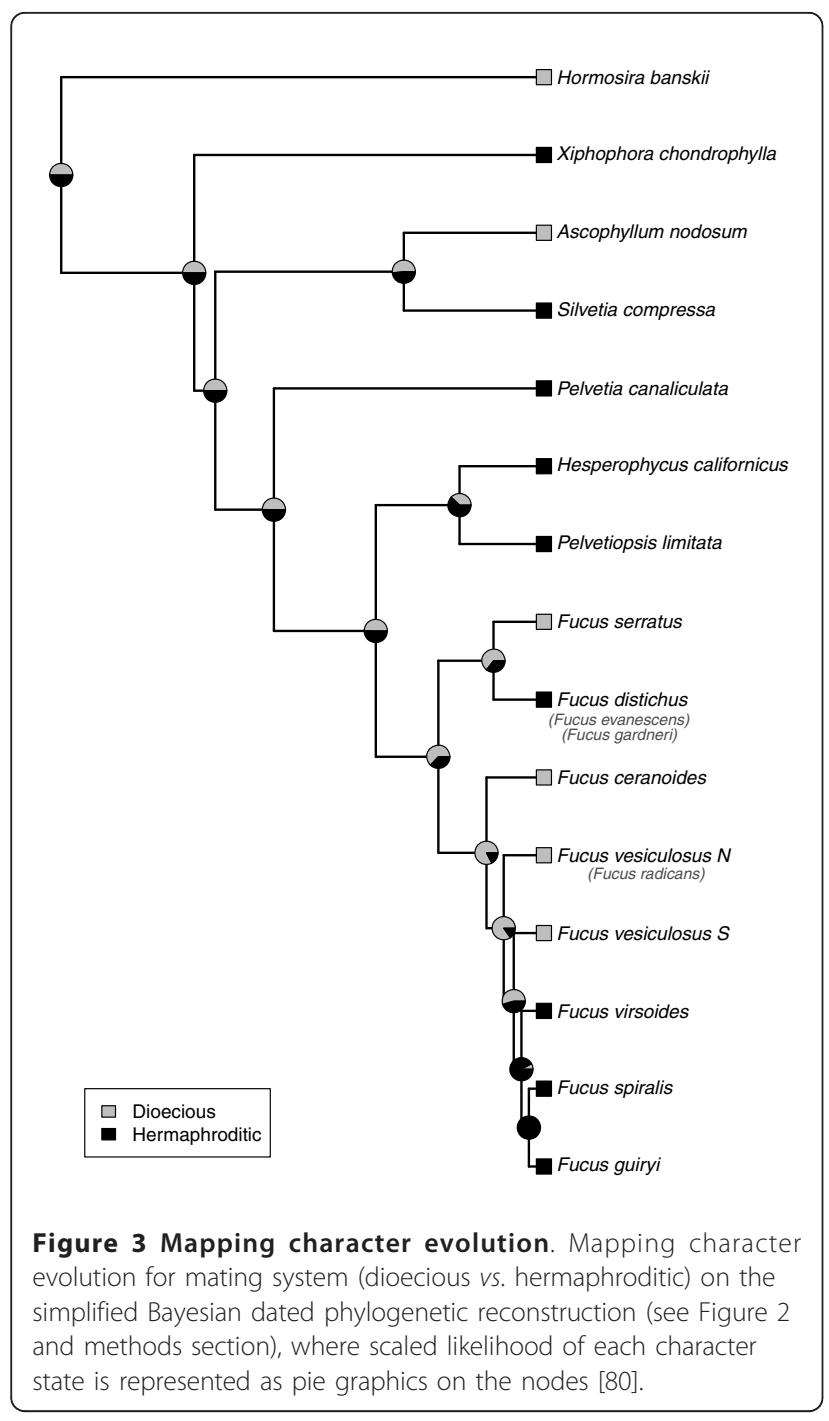

drift of the Australasian landmass towards Eurasia in the Miocene and a gradual decrease in global temperatures (14-12 Ma, see Figure 2; [40]), which would have favored crossing of the equatorial fringe. The origin of the Fucaceae would then be due to subsequent divergence in the North Pacific.

Our data indicate that four independent Fucaceae lineages crossed the Bering Strait. The first crossing, estimated at 16.4-5.4 Ma (Figure 2), involved the splitting of the Atlantic lineage leading to Pelvetia canaliculata, and could only have taken place during the earliest openings of the Bering Strait suggested for the Late Miocene (13.0-11.0 and 7.3-6.6 Ma; [20]). Pacific diatoms found in Atlantic marine sediments indicate the existence of a strait at that time [20], supporting such early Pacific-Atlantic colonizations. The alternatives to this scenario, other than methodological bias in dating, require either accelerated lineage divergence following the trans-Arctic crossing, or the start of divergence before the trans-Arctic crossing. The latter is unlikely because Pelvetia is currently monotypic with no extant Pacific representatives. While the extreme upper intertidal distribution and stress tolerance of Atlantic P. canaliculata, makes accelerated selective ecological divergence a plausible explanation, it is unnecessary to invoke it if earlier openings of the Bering Strait occurred [20]. A second (and probably later; 11.5-1.1 Ma, Figure 2) trans-Arctic crossing led to the Atlantic genus Ascophyllum, following a split from its Pacific sister genus Silvetia, coincident with the Bering Strait opening at 5.5-5.4 Ma [18]. These results contradict the previous ITS phylogeny of [23] but agree with these data after their re-analysis with better fit models (see methods). It revealed Ascophyllum as sister to the Pacific genus Silvetia and placed the Ascophyllum-Silvetia in a basal clade to the Fucaceae, a hypothesis also raised by [23].

The third (possibly simultaneous) trans-Arctic crossing, and the most successful in terms of subsequent speciation, was the split between the current Hesperophycus-Pelvetiopsis in the Pacific and the lineage leading to Fucus, of which all current species are Atlantic except the circum-Arctic F. distichus complex. This divergence, estimated at 12.2-2.7 Ma, coincides both in time and reproductive mode (shifting from hermaphroditic to dioecious) with the Ascophyllum lineage split from the Silvetia clade. The timing of both lineage splitting events leading to Ascophyllum and Fucus centers around the opening of the Bering Strait 5.5-5.4 Ma when, despite moving against the predominant AtlanticPacific flow, the warmer climate (see Figure 2) might have facilitated stepping stone colonization and migration across the Arctic. Ancestral state reconstructions (Figure 4) place the most recent common ancestor of Fucus in the Atlantic/Arctic ocean basin, suggesting that it was here that subsequent diversification took place. The alternative hypothesis, deserving further study, is that the opening of the Bering Strait led to a vicariant split between clade 1 in the Pacific and clade 2 in the Atlantic. An additional interesting question remains as to why, following similar colonization conditions by ecologically similar lineages, Ascophyllum is currently a monotypic genus whereas Fucus underwent relatively extensive speciation.

The fourth trans-Arctic crossing involved the evolutionary history of Arctic vicariance in Fucus clade 1. The ancestor to clade 1 was estimated as Atlantic (Figure 4), and the Atlantic-Pacific dichotomy might be more accurately described as Arctic to agree with the geographical and ecological range of current representatives. The ancestral state reconstruction implies that $F$. serratus/F. distichus diverged in the Atlantic and/or within the Arctic basin, which represent the same side 
Table 3 Tests of biogeographical hypotheses

\begin{tabular}{|c|c|c|c|c|c|c|c|c|c|c|c|}
\hline Scenario & Df & $s A$ & $s B$ & $S A B$ & $x A$ & $x B$ & $d A$ & $d B$ & logLik & $A I C$ & $P$ \\
\hline Assymetric parameters & 7 & 0.195 & 0.019 & 1.225 & 0.049 & 0.000 & 0.070 & 0.000 & -46.828 & 107.656 & \\
\hline Assymetric speciation & 5 & 0.164 & 0.020 & 1.225 & \multicolumn{2}{|c|}{$x A \sim x B$} & \multicolumn{2}{|c|}{$d A \sim d B$} & -48.775 & 107.550 & NS \\
\hline Assymetric extinction & 5 & \multicolumn{2}{|c|}{$S A \sim s B$} & 1.225 & 0.058 & 0.029 & \multicolumn{2}{|c|}{$d A \sim d B$} & -51.580 & 113.160 & $* *$ \\
\hline Symmetric parameters & 4 & \multicolumn{2}{|c|}{$S A \sim s B$} & 1.225 & & & \multicolumn{2}{|c|}{$d A \sim d B$} & -51.636 & 111.270 & ** \\
\hline Sink-sink system & 5 & \multicolumn{2}{|c|}{$S A \sim S B$} & 1.225 & & & 0.075 & 0.000 & -50.172 & 110.340 & * \\
\hline Unconstrained DEC & 2 & \multicolumn{2}{|c|}{-} & - & \multicolumn{2}{|c|}{0.032} & \multicolumn{2}{|c|}{0.000} & -13.25 & - & - \\
\hline Stratified biogeographical DEC model & 2 & & & - & & & \multicolumn{2}{|c|}{0.061} & -16.45 & - & - \\
\hline
\end{tabular}

Speciation (s), extinction $(x)$ and dispersal $(d)$ rates between the two biogeographical regions on either side of the Bering Strait (A, Pacific Ocean; B, Atlantic Ocean, including most of the Arctic). Complete asymmetric model and different scenarios of state-independent and state-dependent diversification (rates constrained to be equal), and unidirectional and bidirectional dispersal were tested: 1) asymmetric model; 2) asymmetric speciation, state-independent extinction and dispersal rates; 3) asymmetric extinction, state-independent speciation and dispersal rates; 4) symmetric parameters; 7) Sink-sink system [86]. Log-likelihood, Akaike information criteria (AIC) and log-likelihood ratio test $(\mathrm{P})$ are also provided for comparison between models. Dispersal and local extinction parameters estimated by DEC models are also shown [88,89].

of the Bering Strait, with subsequent invasion of the Pacific by the $F$. distichus lineage. Although Atlantic (previously named F. evanescens) and Pacific (previously named $F$. gardneri) samples of $F$. distichus used in this phylogeny correspond to the geographical extremes of the ranges found within the $F$. distichus complex $[24,46]$, estimated Pacific-Atlantic divergence times based on coalescence are very recent (mid-Pleistocene) (Figure 2). Thus our data do not contradict the current designation of these lineages as a single species, F. distichus (see [32]), but do not rule out low levels of vicariant divergence (Figure 1), also in agreement with Coyer et al. [32].

\section{Driving south: a biogeographical hypothesis for the} evolution of Fucus clade 2

The earliest branching member of the clade is the dioecious lineage $F$. ceranoides. The contemporary cold-

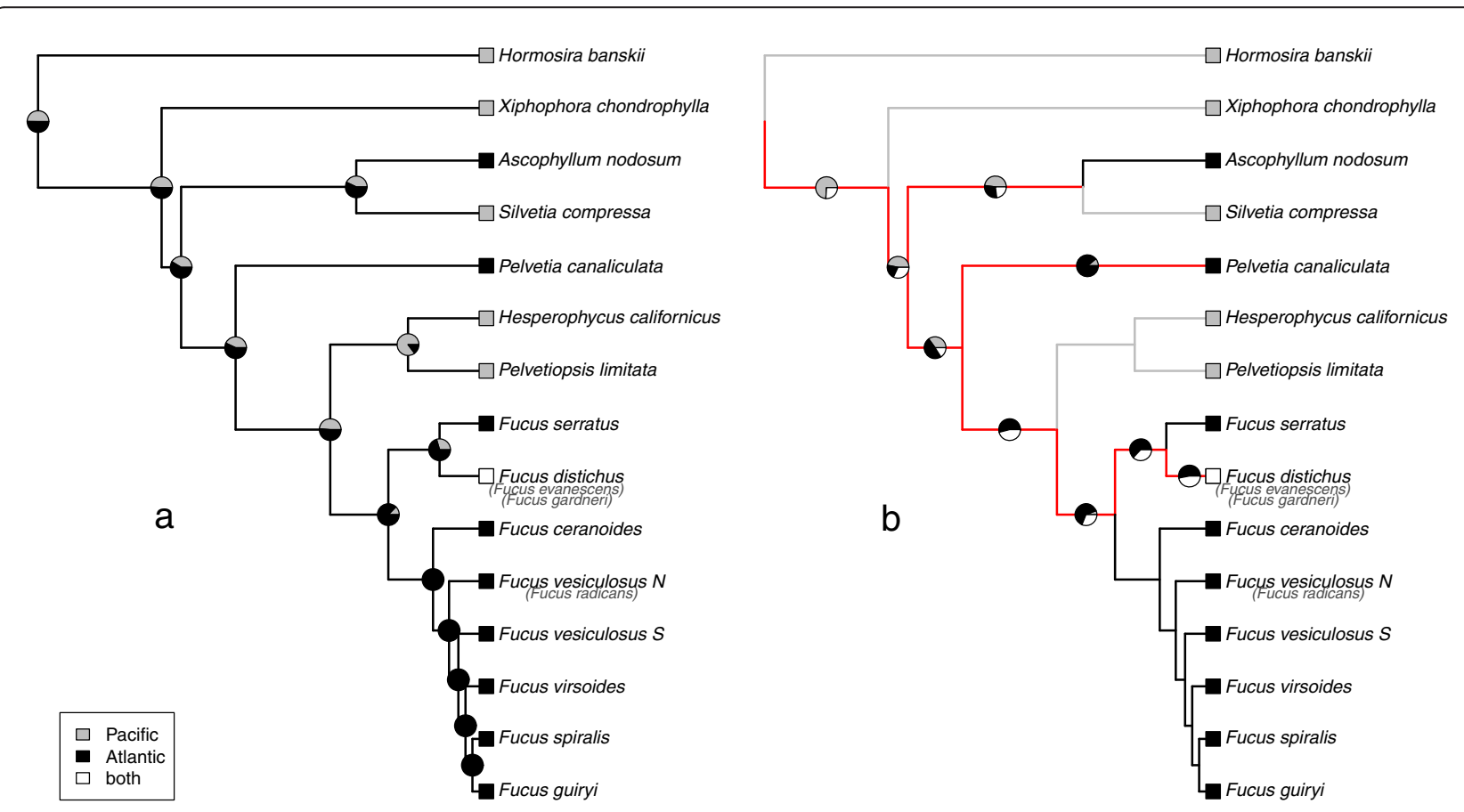

Figure 4 Mapping character evolution. Mapping character evolution for biogeographic range, where scaled likelihood of each character state is represented as pie graphics on the nodes (a) [80]. Ancestral range subdivision/inheritance biogeographic scenarios, where color on branches shows hypothesised scenario (b) [88,89]; unsolved branch-scenarios are coloured in red but then, scaled likelihood meaning either side of Bering Strait, thus Arctic and Atlantic vs. Pacific is provided. Character evolution is traced on the simplified Bayesian dated phylogenetic reconstruction (see Figure 2 and methods section). Note that F. distichus was analysed as either Atlantic and Pacific. 
temperate distribution of $F$. ceranoides from Norway to North Portugal is similar to the present day range of $F$. serratus in clade 1 [33], which has a coincident speciation time (Figure 2). Nuclear and organelle phylogenies for $F$. ceranoides are congruent in the southern part of the range, while to the north of the English Channel populations harbour exclusively introgressed organellar genomes captured from $F$. vesiculosus that have spread by genetic surfing during postglacial range expansion [36]. This is not the only case of organellar introgression in this clade [26], emphasizing that organellar sequences can be equivocal for phylogenetic inferences in taxa prone to introgression. F. vesiculosus was shown here to be polyphyletic. Two clades were well separated within $F$. vesiculosus according to their range distributions from: i) Iberia to the south versus, ii) the English Channel to the north. These are also differentiated at microsatellite loci $[25,29,47]$, both in allelic frequencies and in the presence of private alleles, but were not recovered previously with mitochondrial markers $[24,26]$, possibly due to masking by extensive organellar introgressionexpansion dynamics that can take place in Fucus species [36]. Importantly, the southern $F$. vesiculosus share a common ancestor with the remaining members of the same lineage, all of which are hermaphroditic. The two divergent lineages in what is currently named $F$. vesiculosus coincide in present distribution with two marine glacial refugia (Iberia and Brittany; [3]). A split of southern $F$. vesiculosus into two clades suggested by certain analyses (Figure 1 and Additional file 4 and 5) deserves further investigation, but could result from introgressive signatures with $F$. guiryi, which may be found in sympatry in some regions $[11,25,47]$, but not in the southernmost sites where the two species are allopatric $[11,30]$ (Figure 1 and Additional file 5).

Divergence of the hermaphroditic lineage in clade 2 (leading to F. virsoides, F. spiralis and F. guiryi) from their dioecious sister lineage may have been driven or at least maintained by reproductive isolation derived from a selfing reproductive mode. Once a hermaphroditic lineage arises, selfing may follow rapidly, reinforcing genetic isolation and favouring subsequent differentiation [48]. Selfing can be advantageous in marginal and/ or stressful habitats to conserve local adaptation and for reproductive assurance, both key selective pressures for intertidal broadcast spawners such as Fucus [49].

The earliest divergence within the hermaphroditic clade is $F$. virsoides, currently restricted to the northern Adriatic Sea, a possible remnant from a more extensive distribution during a cooler glacial period. More recently, the lineage split between $F$. guiryi and F. spiralis coincides with southern $v s$. northern ranges. Along the southern range, Fucus species are segregated by habitat, i.e., open coast (F. guiryi) versus estuaries and coastal lagoons (southern $F$. vesiculosus), whereas further north, where they co-occur, F. guiryi undergoes introgression $[11,25,26,47]$, which was hypothesized to reflect the absence of reinforcement during allopatric evolution [47]. The phylogenetic position of the high intertidal $F$. spiralis reported here is incongruent with mitochondrial data [26], possibly another case of extensive organellar introgression in this genus.

Our data, like previous ITS and mitochondrial data $[23,24]$, do not resolve the relationship between the recently described $F$. radicans and $F$. vesiculosus. This is unsurprising given the suggested timescale of divergence (hundreds to at most thousands of years [27]), since the opening of the Baltic Sea (ca. 7 Kya), possibly facilitated by high adaptive potential of the common ancestor with F. vesiculosus $[10,50]$.

\section{Mating system evolution}

The evolution of reproductive mode in the Fucaceae has followed a reticulate pattern of alternating dioecious and hermaphroditic lineages that challenges current understanding of mating system evolutionary trends (Figure 3; e.g., $[15,16])$. Methods to estimate the influence of species' traits on lineage diversification establish hermaphroditic lineages as ancestral in the family, evolving into dioecious lineages, folowed by switches from dioecy to hermaphroditism in the genus Fucus, contradicting earlier suggestions $[24,51]$. There is considerable support for hermaphroditism (cosexuality) as the ancestral state in plants [15], and simple genetic mechanisms of dioecious sex determination and sex chromosome evolution have been proposed (reviewed by $[52,53]$ ). It is intriguing that two of the three novel Atlantic lineages presumably coincided with a switch to dioecy (Ascophyllum and Fucus). The evolution of dioecy and increased evolutionary potential [16] may therefore have facilitated long-term establishment in the Atlantic, driven in part by the availability of extensive and novel habitats favouring large and dense populations. In contrast, hermaphroditic lineages are better colonizers of marginal habitats via increased reproductive assurance and the maintenance of locally adaptive traits.

The recent evolutionary trajectory of reproductive mode has been a switch towards hermaphroditism, and highly selfing mating systems, at least within Fucus lineage $2[29,30]$. The transition from outcrossing to selfing is common in plants [54], but with little evidence for reversion, suggesting an evolutionary dead-end $[16,55]$. This in turn suggests that the hermaphroditic ancestors of the dioecious lineages leading to Ascophyllum and Fucus were not highly selfing.

\section{Conclusions}

The analysis of concatenated cDNA sequences from 13 partial coding regions resolved the evolutionary history of 
the Fucaceae, and allowed the dating of splitting events and tests of hypotheses concerning recent drivers of speciation. Diversification of the family could be placed in the Late-Mid Miocene. Four independent trans-Arctic colonisations were inferred, coincident with the split of the lineages leading to 1) Pelvetia canaliculata, 2) Ascophyllum nodosum, 3) the genus Fucus, and more recently 4) in the $F$. distichus species complex. Two dioecious lineages (originating the genera Ascophyllum and Fucus) evolved in the Atlantic/Arctic from hermaphroditic ancestors. Despite an earlier origin of the genus Fucus, most current species have evolved within a relatively short time frame starting 4-3 Ma in the Pleistocene. Both Fucus clades contain dioecious and hermaphroditic lineages, and recent speciation trends in clade 2 have given rise to hermaphroditic lineages from dioecious ancestors. Recent radiation in Fucus clade 2 coincides with divergence in physiological tolerance to environmental stresses and colonization of novel habitats at range edges, suggesting ecological speciation. In this clade, selfing lineages occur in the most extreme habitats, likely linked with reproductive assurance and the maintenance of local adaptation.

\section{Methods}

\section{Taxa distribution and sampling}

All species of Silvetia and the monotypic genera Pelvetiopsis and Hesperophycus occur exclusively in the Pacific. Pelvetia and Ascophyllum are monotypic genera occurring exclusively in the Atlantic. All species of Fucus occur in the Atlantic and its adjacent seas except F. distichus (sensu lato), which is also found in the Pacific. At least 3 individuals from each of the 6 genera of Fucaceae were used in all analyses except for Ascophyllum and Pelvetia (2 individuals; Additional file 2).

Samples were collected from several locations from where it was possible to transport specimens alive or deep frozen in dry ice to prevent RNA degradation: 1 Pacific, 7 North Atlantic, 1 Baltic and 1 Mediterranean regions were used (Additional file 2). Sequences from a previous study [11] were also added (shown in Additional file 2). Fresh material was lyophilized and samples were stored at room temperature with silica drying crystals prior to RNA extraction [56].

\section{RNA extraction, cDNA synthesis and amplification}

Lyophilized tissue was powdered for $5 \mathrm{~min}$ on a Mixer Mill (MM 300 - Retsch, Germany) and total RNA was isolated using the extraction method as described in Pearson et al. [56]. RNA integrity was confirmed by electrophoresis on $1.2 \%$ denaturing agarose gels. For reverse transcription, a solution of $1 \mu \mathrm{g}$ total RNA, 1 $\mathrm{mM}$ dNTPs and $5 \mu \mathrm{M}$ oligo $\mathrm{d}(\mathrm{T})$ was denatured at $70^{\circ} \mathrm{C}$ for $5 \mathrm{~min}$ and placed on ice for $>1 \mathrm{~min}$. First Strand Buffer, DTT $(0.1 \mathrm{M})$, RNase OUT and SuperScript ${ }^{\mathrm{TM}}$
III (Invitrogen) were added, the mix was incubated at $55^{\circ} \mathrm{C}$ for $1-2 \mathrm{~h}$, and the reaction was then heat-inactivated at $80^{\circ} \mathrm{C}$ for $10 \mathrm{~min}$. A total of 13 coding regions were selected for sequence analysis (Additional file 1). Specific primers were designed from Expressed Sequence Tag (EST) consensus sequences in F. vesiculosus or F. serratus [57] using Primer3 software version 0.4.0 [58]. PCR was carried out in $20 \mu \mathrm{l}$ reaction volumes containing 1-3 $\mu \mathrm{l}$ of cDNA (1/40 dilution) as template, $1.5 \mathrm{mM}, 0.2 \mu \mathrm{M}$ dNTPs, $0.5 \mu \mathrm{M}$ of each primer and $1 \mathrm{U}$ of Taq polymerase, with the following conditions: initial denaturation at $94^{\circ} \mathrm{C}$ for $3 \mathrm{~min} ; 35$ cycles of denaturation at $94^{\circ} \mathrm{C}$ for $20 \mathrm{~s}$, annealing at $58^{\circ} \mathrm{C}$ for $90 \mathrm{~s}$ and a final extension at $65^{\circ} \mathrm{C}$ for $5 \mathrm{~min}$. Products were sequenced at the Centre of Marine Sciences, University of Algarve (ABI 3130xl). The resulting chromatograms were analyzed using CodonCode Aligner v1.6.3 (CodonCode Corp., Dedham, Massachusetts, USA).

\section{Outgrouping procedure}

The specificity of the cDNA primer sequences was too great to allow amplification of gene products outside the family Fucaceae, specifically for the sister families Xiphophoraceae and Hormosiraceae [23,38,59]. In order to include in the multi-gene phylogenetic estimations the sister families outside the Fucaceae, we used additional ITS sequence information from a previous study [23], but applyed more advanced methodological analyses. Those sequences were first re-aligned using MAFFT v6 [60], using the E-INS-i option recommended for sequences with multiple conserved domains and long gaps [61]. K80 plus I plus G was selected as the best model fit to the nucleotide data set based on AIC as implemented in MrModeltest [62]. ITS dataset was analysed using maximum likelihood and Bayesian approaches as described above (see multi-gene phylogenetic analyses section). This rooted phylogenetic resolution of the genera in the Fucaceae based on ITS sequences was used to infer the basal genera of the family Fucaceae. These genera, Ascophyllum and Silvetia were used as outgroup to root the multi-gene phylogenetic analyses aimed at inferring the order of the previously unresolved speciation events.

\section{Multi-gene phylogenetic analyses}

The cDNA sequence dataset (Additional file 2) was aligned first using MAFFT v6 [60], using the G-INS-i option recommended for sequences with global homology [61]. Models of sequence evolution were selected based on Akaike Information Criterion (AIC) as implemented in MrModeltest v2.3 [62] for each of the 13 partitions defined by each gene: Hasegawa-Kishino-Yano model (HKY; [63]) was most appropriate for the 1st, 11th and 12th partitions, HKY plus I for 5th, 6th, 7th 
and 10th partitions and HKY plus G for 13th partition; Kimura 2-parameter (K80; [64]) for 8th and 9th partitions, plus I for 2nd partition; Symmetrical model plus G (SYM; [65]) for 3rd partition; and General Time Reversible (GTR; [66]) plus I for 4th partition. The combined data set was analyzed as one partition using the GTR model plus I and G.

Maximum likelihood bootstrap analysis with 999 replicates was performed to infer the phylogenetic relationships for the combined data set using PhyML v3.0.1 [67]. The substitution parameters were estimated over a neighbor-joining tree. Tree searching operations were set to best of nearest-neighbour interchange (NNI) with subtree pruning and regrafting (SPR). Partitioned Bremer support analysis [68] was performed using TreeRot v2 $[69,70]$, in order to provide a measure of how the different partitions of the data contributed to the Decay index for each node in the context of the combined data analysis.

Bayesian inferences were performed with MrBayes v3.1.2 [71]. For the partitioned analysis, the substitution model and branch length estimates were allowed to vary independently in each partition. General forms of these models were used since there is a specific recommendation against the use of fixed priors for a and I in the software manual in order to explore more efficiently different values of these parameters. The number of generations was set to $10^{6}$ with a sampling frequency of 1000 generations in a dual running process with four chains per run [72]. Majority rule consensus trees were computed after discarding the first $25 \%$ of the trees as burn-in, which were saved prior to MCMC convergence. Support for clades given by posterior probabilities was thus represented by the majority rule percentage.

\section{Evolutionary divergence time estimations}

Two major problems preclude a well-defined fossil record for the brown algae: a) almost all brown algae are uncalcified; b) misidentification due to the morphological similarities with some members of the Rhodophyta [37]. Brown algae are known, however, from Miocene rocks in California and diatomaceous sediments in Central Europe [73,74]. Some of these can be directly compared to genera of the extant family Sargassaceae, as Cystoseirites (similar to Cystoseira) or Paleohalidrys (which has modern representatives) that are in the order Fucales, and provide a valuable framework for evolutionary parameter estimation and molecular dating of Fucaceae [37].

Likelihood ratio tests significantly rejected a strict (uniform) molecular clock for the alignment. Node age estimates were therefore obtained by Bayesian-calibrated phylogenies using an uncorrelated log-normal relaxed clock as suggested for protein-coding genes in a broad variety of species [75]. Gene-specific gamma-distributed rate heterogeneity among sites and partition into codon position allowed separate estimation of non-synonymous and synonymous sites [76]. The HKY model of evolution was defined as proposed by Shapiro et al. [77] for coding regions. Tree priors were fixed on the coalescent, using constant population size and expansion growth, and on Yule speciation models of demographic history. Monophyletic constraints were imposed for the nodes that were used to calibrate the evolutionary rates. Uniform priors were used for the tmrca of the Fucaceae family (Aquitanium to Tortonian age from Miocene epoch: minimum age of $7 \mathrm{Myr}$; maximum age of 23 Myr; based on [38] and previous analyses using 5.8S ribosomal nuclear DNA together with ITS-1 and ITS-2 regions; see Additional file 6). Tree priors were used for the tmrca of the Fucus genus. MCMC chains were run in BEAST v1.5.4 for $10^{7}$ generations, with burn-in and sampling as described above [78]. Identical sequences or those with genetic distances less than 0.002 were removed prior to the analyses in order to prevent nodes without longitude on the dated reconstruction. Convergence and stationarity of the chains was evaluated by plotting trace files in Tracer v. 1.4 [78]. Phylogenetic trees were represented using $\mathrm{R}$ statistical software v2.13.0 [79] together with "ape v2.5-1" library [80].

\section{Estimation of ancestral character states and traits associated with lineage diversification}

Methods to estimate the influence of species' traits on lineage diversification have improved with recent advances in the detection of phylogenetic signatures of state-dependent speciation and extinction [81]. In particular, hypotheses of trait acquisition for a binary character and asymmetry in the direction of trait evolution can now be tested through the formulation of a model [81]. For example, mating system is likely to confer unequal probabilities of speciation and extinction. Two states of the character were used for mating system evolution (dioecious $v s$. hermaphroditic), under one-parameter (MK1) and asymmetrical 2-parameter (MK2) Markov kstate models [82-84]. The binary state speciation and extinction model (BiSSE, [84]) was also used to avoid incorrect rejection of irreversible evolution [81].

Alternative hypotheses concerning geographic range evolution and diversification (Pacific vs. Atlantic), were also tested using a geographic state speciation and extinction model (GeoSSE; [85]). We applied the model to test the relative contributions of speciation, extinction, and dispersal to diversity differences between oceans [85]. We also considered different combinations of state-independent and state-dependent diversification, and dispersal (Table 2). 
BiSSE and GeoSSE model assumptions were satisfied through the use of the best rooted tree based on the dated ITS and multi-gene phylogenies: i) rooted phylogenetic tree with branch lengths; ii) contemporaneous terminal taxa and; iii) ultrametric tree [81]. Characters were binary with known state for each of the terminal taxa. Models were fitted by maximum likelihood nonlinear optimization from a heuristic starting point based on the character-independent birth-death model. Model results were evaluated and compared using the logarithm of the likelihood and the AIC values for the final fitted models. Ancestral character states and the associated uncertainty were also estimated from the scaled likelihood of each character state. Analyses were carried out using the R statistical software [79], with "diversitree v0.7-2" and "ape v2.5-1" packages [80,85-87].

The dispersal-extinction-cladogenesis (DEC) likelihood model was also implemented to infer geographic ancestry and estimate rates of dispersal and local extinction $[88,89]$. Unconstrained and stratified biogeographical models were considered. The latter model stratified the phylogeny into different time slices, reflecting the Bering Strait configuration over time while considering divisions that retained enough phylogenetic events [90]. Five time slices were chosen that reflect the hypothesized openings of the Bering Strait during the history of Fucaceae: between 13 and $11 \mathrm{Ma}$, between 7.3 and 6.6 $\mathrm{Ma}$, between $5.5 \mathrm{Ma}$ and 4.0, between $3.6 \mathrm{Ma}$ and 3.2, and between 2.5 and the present day (see Figure 2 for a detailed time-placement of the recurrent opening events $[18,20])$. For each time slice, we defined a $\mathrm{Q}$ matrix in which transition rates were made dependent on the geographical connectivity between areas (i.e. opening and closing of the Bering Strait). Lagrange analyses were configured using the web application from the same authors (URL: http://www.reelab.net/lagrange/configurator; $[88,89])$ and run locally using Lagrange v.20110117 [89]. Results were summarized and plotted using the $\mathrm{R}$ statistical software [79] with the "ape v2.5-1" package [80].

\section{Additional material}

Additional file 1: Incorporated CDNA sequences. Annotations of coding region transcripts used in this study. Total and used length expressed in base pairs (bp) and amino acids (aa) as well as primer sequences are presented. As $P$, we indicate the partition number for each region used in mixed analyses.

Additional file 2: Sampling sites and GeneBank accession numbers of all incorporated CDNA sequences.

Additional file 3: Separate analyses of ribosomal nuclear DNA together with ITS regions (see Methods section: estimation of ancestral character states). Phylogenetic reconstructions using $5.8 \mathrm{~S}$ ribosomal nuclear DNA together with ITS-1 and ITS-2 regions (re-analysis of data from [23] after testing for best fit model). Values shown are the $50 \%$ majority rule percentage of support for clades given by Bayesian posterior probabilities from one million generation MCMC analysis (above) and the 50\% majority rule consensus tree of maximum likelihood bootstraps (below). H. banskii was used as outgroup to root the phylogenetic reconstructions (as in [23]). These results were also used to root the multi-gene phylogenetic trees since the specificity of primers used to amplify transcriptomic regions in the Fucaceae did not allow amplification outside this group. Topology is based on maximum likelihood reconstruction.

Additional file 4: Bayesian dating of Fucaceae diversification using cDNA. Full tree showing the Bayesian dated phyloreconstruction using the 13 coding loci. Node ages in million years (Myr) correspond to the time scale at the bottom of the figure.

Additional file 5: Multi-gene phylogenetic reconstruction from cDNA (see Methods section: Multi-gene phylogenetic analyses of cDNA sequences) including introgressed sequences. Multi-gene phylogenetic relationships as shown in Figure 1 but adding sequences of F. guiryi from northern Portugal, where the species co-occurs in sympatry with $F$. vesiculosus and $F$. spiralis, creating an introgressed range for $F$. guiryi that continues northwards $[11,25,26,47]$. Methods are the same as described for Figure 1. Comparison of this tree with Figure 1 illustrates the effect of introgressed contact regions in preventing phylogenetic resolution, by confounding vertical lineage splitting with horizontal introgressive mixing.

Additional file 6: Bayesian dating of Fucaceae diversification using nuclear ribosomal DNA: the $5.8 \mathrm{~S}$ gene together with ITS-1 and ITS2 regions. Bayesian dated phyloreconstruction using nuclear ribosomal DNA, the $5.8 \mathrm{~S}$ together with ITS-1 and ITS-2 regions. Node ages in million years (Myr) with their 95\% HPD interval correspond to the time scale at the bottom of the figure. Node age estimates were obtained using an uncorrelated log-normal relaxed clock under GTR model of evolution. Tree priors were fixed on Yule speciation model of demographic history. One individual of Cystoseira neglecta, C. osmundacea and C. setchellii species were included as representatives of the family Sargassaceae for the inferences ([94]; accession numbers: AY542816, AY542819 and AY542812). Monophyletic constraints were imposed for the nodes that were used to calibrate the evolutionary rates. Normal priors were used for the times to the most recent common ancestor (tmrca) of Fucaceae and Sargassaceae families (Medium Chattium to Aquitanium age from Miocene epoch: mean 22.5 million years (Myr); standard deviation 2.5 Myr [37]). Results were processed as described in the methods section.

\section{Abbreviations}

AIC: Akaike information criteria; BiSSE: Binary state speciation and extinction model; DEC: Dispersal-extinction-cladogenesis model; GeoSSE: Geographic state speciation and extinction model; ITS: Internal Transcribed Spacer; Myr: Million years; Ma: Million years ago; mrca: Most recent common ancestor; SNP: Single nucleotide polymorphism; v: Software version; Kyr: Thousands years; tmrca: Time to the most recent common ancestor.

\section{Acknowledgements}

Thanks to J. Nylander for the Perl scripts to manipulate MrBayes tree and parameter files. Thanks to R.A. Rohde.We appreciate Ron Blakey's kindness, giving access to excellent paleo-geographic reconstructions along Earth landmass evolution. We are grateful to P. Raimondi, Kyle Walters and Haven Livingston (UC Santa Cruz, USA), G. Zardi, and K. Nicastro (CCMAR) for sample collection; samples of $F$. radicans were obtained in collaboration with K. Johannesson, L. Kautsky and R. Pereyra (Tjärnö Marine Laboratory, Sweden). Thanks to three anonymous reviewers and also the editor who improved the manuscript with their comments and suggestions during the revision process. This research was supported by funding from the Portuguese Science Foundation (FCT), NoE Marine Genomics Europe (G.A. Pearson) and the EU project EDEN (E.A. Serrão). F. Cánovas was supported by a post-doctoral fellowship from FCT. Finally, we acknowledge the late Jimmy Hendrix, who's version of "Driving South" provided the inspiration for the title. 


\section{Authors' contributions}

The study was conceived by GAP and EAS. GAP supervised the project. CFM performed all the laboratory work. FC performed all the phylogenetic analyses. FC, GAP and EAS wrote the manuscript. All authors read and approved the final manuscript.

Received: 7 September 2011 Accepted: 21 December 2011 Published: 21 December 2011

\section{References}

1. Palumbi SR: Genetic Divergence, Reproductive Isolation, and Marine Speciation. Annual Review of Ecology and Systematics 1994, 25:547-572.

2. Wares J, Cunningham C: Phylogeography and historical ecology of the North Atlantic intertidal. Evolution 2001, 55:2455-2469.

3. Maggs C, Castilho R, Foltz D, Henzler C, Jolly M, Kelly J, Olsen J, Perez K, Stam W, Väinölä R, Viard F, Wares J: Evaluating signatures of glacial refugia for North Atlantic benthic marine taxa. Ecology 2008, 89(11 Suppl):S108-22.

4. Schluter D: Ecological causes of adaptive radiation. American Naturalist 1996, 148:S40-S64.

5. Rüber L, Van Tassell J, Zardoya R: Rapid Speciation and Ecological Divergence in the American Seven-Spined Gobies (Gobiidae, Gobiosomatini) Inferred from a Molecular Phylogeny. Evolution 2003, 57(7):1584-1598

6. Ingram T: Speciation along a depth gradient in a marine adaptive radiation Speciation along a depth gradient in a marine adaptive radiation. Proceedings of the Royal Society of London, series B 2011, 278:613-618.

7. Taylor M, Hellberg M: Marine radiations at small geographic scales: speciation in neotropical reef gobies (Elacatinus). Evolution 2005, 59:374-385.

8. Johannesson K: Evolution in Littorina: ecology matters. Journal of Sea Research 2003, 49:107-117.

9. Rundle H, Nosil P: Ecological speciation. Ecology Letters 2005, 8:336-352.

10. Lago-Leston A, Mota C, Kautsky L, Pearson G: Functional divergence in heat shock response following rapid speciation of Fucus spp. in the Baltic Sea. Marine Biology 2010, 157:683-688.

11. Zardi G, Nicastro K, Canovas F, Ferreira-Costa J, Serrão E, Pearson G: Adaptive traits are maintained on steep selective gradients despite gene flow and hybridization in the intertidal zone. PloS one 2011.

12. Butlin R, Galindo J, Grahame J: Sympatric, parapatric or allopatric: the most important way to classify speciation? Philosophical transactions of the Royal Society of London. Series B 2008, 363:2997-3007.

13. Schluter D: Ecological speciation. Trends in Ecology and Evolution 2001, 16:372-380.

14. Palumbi SR: Marine speciation on a small planet. Trends in Ecology \& Evolution 1992, 7(4):114-118.

15. Charlesworth D: Plant sex determination and sex chromosomes. Heredity 2002, 88:94-101.

16. Takebayashi N, Morrell P: Is self-fertilization an evolutionary dead end? Revisiting an old hypothesis with genetic theories and a macroevolutionary approach. American Journal of Botany 2001, 88:1143-1150

17. Marincovich L, Gladenkov A: Evidence for an early opening of the Bering Strait. Nature 1999, 397:149-151.

18. Gladenkov A, Oleinik A, Marincovich L, Barinov K: A refined age for the earliest opening of Bering Strait. Palaeogeology, Palaeoclimatology and Palaeoecology 2002, 183:321-328.

19. Lindstrom SC: The Bering Strait connection: dispersal and speciation in boreal macroalgae. Journal of Biogeography 2001, 28:243-251.

20. Svitoch A, Taldenkova E: Recent history of the Bering Strait. Oceanology 1994, 34:400-404.

21. Greene C, Pershing A, Cronin T, Ceci N: Arctic climate change and its impacts on the ecology of the North Atlantic. Ecology 2008, 89:S24-S38.

22. Peters A, van Oppen M, Wiencke C, Stam W, Olsen J: Phylogeny and historical ecology of the Desmarestiaceae (Phaeophyceae) support a southern hemisphere origin. Journal of Phycology 1997, 33:294-309.

23. Serrão E, Lawrence A, Brawley S: Evolution of the Fucaceae (Phaeophyceae) inferred from nrDNA-ITS. Journal of Phycology 1999, 35:382-394.
24. Coyer J, Hoarau G, Oudot-Le Secq M, Stam WT, Olsen JL: A mtDNA-based phylogeny of the brown algal genus Fucus (Heterokontophyta; Phaeophyta). Molecular Phylogenetics and Evolution 2006, 39:209-222.

25. Billard E, Serrão E, Pearson G, Destombe C, Valero M: Fucus vesiculosus and spiralis species complex: a nested model of local adaptation at the shore level. Marine Ecology Progress Series 2010, 405:163-174.

26. Coyer J, Hoarau G, Costa J, Hogerdijk B, Serrão E, Billard E, Valero M, Pearson G, Olsen J: Evolution and diversification within the intertidal brown macroalgae Fucus spiralis/Fucus vesiculosus species complex in the North Atlantic. Molecular Phylogenetics and Evolution 2011, 58:283-296.

27. Pereyra $R$, Bergström $L$, Kautsky $L$, Johannesson $K$ : Rapid speciation in a newly opened postglacial marine environment, the Baltic Sea. BMC Evolutionary Biology 2009, 9:1-9.

28. Billard E, Dauguin C, Pearson G, Serrão E, Engel C, Valero M: Genetic isolation between three closely related taxa Fucus vesiculosus, F. spiralis and F. ceranoides. Journal of Phycology 2005, 41:900-905.

29. Engel C, Daguin C, Serrão E: Genetic entities and mating system in hermaphroditic Fucus spiralis and its close dioecious relative $F$. vesiculosus (Fucaceae, Phaeophyceae). Molecular Ecology 2005, 14:2033-2046.

30. Perrin C, Daguin C, Van De Vliet M, Engel C, Pearson G, Serrão E: Implications of mating system for genetic diversity of sister algal species Fucus spiralis and Fucus vesiculosus (Heterokontophyta, Phaeophyceae). European Journal of Phycology 2007, 42:219-230.

31. Tatarenkov A, Bergström $L$, Jönsson R, Serrão E, Kautsky L, Johannesson $K$ : Intriguing asexual life in marginal popu- lations of the brown seaweed Fucus vesiculosus. Molecular Ecology 2005, 14:647-651.

32. Coyer J, Hoarau G, Van Schaik J, Luijckx P, Olsen JL: Trans-Pacific and trans-Arctic pathways of the intertidal macroalga Fucus distichus $\mathrm{L}$. reveal multiple glacial refugia and colonizations from the North Pacific to the North Atlantic. Journal of Biogeography 2010.

33. Coyer J, Peters A, Stam W, Olsen J: Post-Ice age recolonization and differentiation of Fucus serratus L. (Fucaceae: Phaeophyta) populations in Northern Europe. Molecular Ecology 2003, 12:1817-1829.

34. Hoarau G, Coyer J, Veldsink J, Stam W, Olsen J: Glacial refugia and recolonization pathways in the brown seaweed Fucus serratus. Molecular Ecology 2007, 16(17):3606-3616.

35. Muhlin J, Brawley S: Recent versus relic: discerning the genetic signature of Fucus vesiculosus(Heterokontophyta; Phaeophyceae) in the northwestern Atlantic. Journal of Phycology 2009, 45:828-837.

36. Neiva J, Pearson G, Valero M, Serrão E: Surfing the wave on a borrowed board: range expansion and spread of introgressed organellar genomes in the seaweed Fucus ceranoides L. Molecular Ecology 2010, 19:4812-4822.

37. Taylor T, Taylor E, Krings M: Paleobotany. The biology and evolution of fossil plants Elsevier; 2009.

38. Silberfeld T, Leigh J, Verbruggen H, Cruaud C, de Reviers B, Rousseau F: A multi-locus time-calibrated phylogeny of the brown algae (Heterokonta, Ochrophyta, Phaeophyceae): Investigating the evolutionary nature of the "brown algal crown radiation". Molecular phylogenetics and evolution 2010, 56(2):659-74.

39. Petit J, Jouzel J, Raynaud D, Barkov N, Barnola J, Basile I, Bender M, Chappellaz J, Davis J, Delaygue G, Delmotte M, Kotlyakov V, Legrand M, Lipenkov V, Lorius C, Pépin L, Ritz C, Saltzman E, Stievenard M: Climate and atmospheric history of the past 420,000 years from the Vostok ice core, Antarctica. Nature 1999, 399:429-436.

40. Zachos J, Pagani M, Sloan L, Thomas E, Billups K: Trends, rhythms, and aberrations in global climate $65 \mathrm{Ma}$ to present. Science 2001, 292:686-693.

41. Lisiecki L, Raymo M, Maureen E: A Pliocene-Pleistocene stack of 57 globally distributed benthic d180 records. Paleoceanography 2005, 20

42. Hay W, Deconto R, Wold C, Wilson K, Voigt S, Schulz M, Wold-Rossby A, Dullo WC, Ronov A, Balukhovsky A, Soeding E: Alternative global Cretaceous paleogeography. In The evolution of Cretaceous ocean/climate systems. Edited by: Barrera E, Johnson C. Geological Society of America Special Paper; 1999:1-47.

43. Yang Z, Rannala B: Bayesian phylogenetic inference using DNA sequences: a Markov chain Monte Carlo method. Molecular Biology and Evolution 1997, 14:717-724.

44. Steel M, McKenzie A: Properties of phylogenetic trees generated by Yuletype speciation models. Mathematical Bioscience 2001, 170:91-112.

45. Pybus O, Rambaut A: GENIE: estimating demographic history from molecular phylogenies. Bioinformatics 2002, 18:1404-1405. 
46. Kucera H, Saunders G: Assigning morphological variants of Fucus (Fucales, Phaeophyceae) in Canadian waters to recognized species using DNA barcoding. Botany 2008, 86:1065-1079.

47. Moalic Y, Arnaud-Haond S, Perrin C, Pearson G, Serrão E: Travelling in time with networks: Revealing present day hybridization versus ancestral polymorphism between two species of brown algae, Fucus vesiculosus and F. spiralis. BMC Evolutionary Biology 2011.

48. Charlesworth D, Charlesworth B: Inbreeding depression and its evolutionary consequences. Annual Review of Ecology and Systematics 1987, 18:237-268.

49. Pearson $\mathrm{G}$, Serrão E: Revisiting synchronous gamete release by fucoid algae in the intertidal zone: fertilization success and beyond? Int Comp Biol 2006, 46: 587-597. International Comparative Biology 2006, 46:587-597.

50. Pearson G, Kautsky L, Serrão E: Recent evolution in Baltic Fucus vesiculosus: reduced tolerance to emersion stresses compared to intertidal (North Sea) populations. Marine Ecology Progress Series 2000, 202:67-79.

51. Billard E, Serrão E, Pearson G, Engel CR, Destombe C, Valero M: Analysis of sexual phenotype and prezygotic fertility in natural populations of Fucus spiralis, F. vesiculosus (Fucaceae, Phaeophyceae) and their putative hybrids. European Journal of Phycology 2005, 40(4):397-407.

52. Ming R, Wang J, Moore P, Paterson A: Sex chromosomes in flowering plants. American Journal of Botany 2007, 94:141-150.

53. Pannell J, Barrett S: Baker's law revisited: reproductive assurance in a metapopulation. Evolution 1998, 52:657-668.

54. Stebbins G: Variation and evolution in plants New York: Columbia University Press; 1950.

55. Stebbins G: Flowering plants. Evolution above the species level Cambridge: Belknap Press of Harvard University Press; 1974.

56. Pearson G, Lago-Leston A, Valente $M$, Serrão E: Simple and rapid RNA extraction from freeze-dried tissue of brown algae and seagrasses. European Journal of Phycology 2006, 41:97-104.

57. Pearson G, Hoarau G, Lago-leston A, Coyer J: An Expressed Sequence Tag Analysis of the Intertidal Brown Seaweeds Fucus serratus (L.) and F. vesiculosus (L.) (Heterokontophyta, Phaeophyceae) in Response to Abiotic Stressors. Marine Biotechnology 2010, 12:195-213.

58. Rozen S, Skaletsky H, Krawetz S, Misener S: Primer3 on the WWW for general users and for biologist programmers. Methods in Molecular Biology 2000, 365-386.

59. Cho G, Rousseau F, de Reviers B, Boo S: Phylogenetic relationships within the Fucales (Phaeophyceae) assessed by the photosystem I coding psaA sequences. Phycologia 2006, 45(5):512-519.

60. Katoh $\mathrm{K}$, Asimenos $\mathrm{G}$, Toh H: Multiple alignment of DNA sequences with MAFFT. In Bioinformatics for DNA sequence analysis. Edited by: Posada D. New York, USA: Humana Press; 2009:39-64

61. Galtier N, Gouy M, Gautier C: SeaView and Phylo_win, two graphic tools for sequence alignment and molecular phylogeny. Computer Applications in the Biosciences 1996, 12:543-548.

62. Nylander J: MrModeltest v2. Xxxx 2004.

63. Hasegawa M, Kishino H, Yano T: Dating the human-ape split by a molecular clock of mitochondrial DNA. Journal of Molecular Evolution 1985, 22:160-174.

64. Kimura M: A simple method for estimating evolutionary rate of base substitutions through comparative studies of nucleotide sequences. Journal of Molecular Evolution 1980, 16:111-120.

65. Zharkikh A: Estimation of evolutionary distances between nucleotide sequences. Journal of Molecular Evolution 1994, 39:315-329.

66. Rodriguez F, Oliver JL, Marin A, Medina JR: The general stochasstic model of nucletide substitution. Journal of Theoretical Biology 1990, 142:485-501.

67. Guindon S, Gascuel O: A simple, fast, and accurate algorithm to estimate large phylogenies by maximum likelihood. Systematic Biology 2003, 52:696-704.

68. Bremer $\mathrm{K}$ : The limits of amino acid sequence data in angiosperm phylogenetic reconstruction. Evolution 1988, 42:795-803.

69. Baker R, DeSalle R: Multiple sources of character information and the phylogeny of Hawaiian Drosophilids. Systematic Biology 1997, 46:654-673.

70. Baker $R, Y u X$, DeSalle R: Assessing the relative contribution of molecular and morphological characters in simultaneous analysis trees. Molecular Phylogenetics and Evolution 1998, 9:427-436.

71. Ronquist F, Huelsenbeck P: MRBAYES 3: Bayesian phylogenetic inference under mixed models. Bioinformatics 2003, 19:1572-1574.
72. Altekar G, Dwarkadas S, Huelsenbeck J, Ronquist F: Parallel Metropoliscoupled Markov chain Monte Carlo for Bayesian phylogenetic inference. Bioinformatics 2004, 20:407-415.

73. Parker B, Dawson E: Non-calcareous marine algae from California Miocene deposits. Nova Hedwigia 1965, 10:273-295.

74. Kovar J: Eine Blätter-Flora des Egerien (Ober-Oligozän) aus marinen Sedimenten der Zentralen Paratethys im Linzer Raum (Österreich). Beiträge zur Paläontologie von Österreich 1982, 9:1-209.

75. Wolf $Y$, Novichkov P, Karev G, Koonin E, Lipman D: The universal distribution of evolutionary rates of genes and distinct characteristics of eukaryotic genes of different apparent ages. Proceedings of the National Academy of Science of USA 2009, 106(18):7273-7280.

76. Doyle J, Gaut B: Evolution of genes and taxa: a primer. Plant Molecular Biology 2000, 42:1-23.

77. Shapiro B, Rambaut A, Drummond AJ: Choosing appropriate substitution models for the phylogenetic analysis of protein-coding sequences. Molecular Biology and Evolution 2006, 23:7-9.

78. Drummond A, Rambaut A: BEAST: Bayesian evolutionary analysis by sampling trees. BMC Evolutionary Biology 2007, 8:1-8.

79. R Development Core Team: $R$ : A language and environment for statistical computing Vienna, Austria; 2009.

80. Paradis E: Analysis of phylogenetics and evolution with $R$ New York: Springer Science+Business Media; 2006.

81. Goldberg $E$, Igić B: On phylogenetic tests of irreversible evolutionEvo. Evolution 2008, 62:2727-2741.

82. Pagel M: Detecting correlated evolution on phylogenies: a general method for the comparative analysis of discrete characters. Proceedings of the Royal Society of London, series B 1994, 255:37-45.

83. Pagel M: The maximum likelihood approach to reconstructing ancestral character states of discrete characters on phylogenies. Systematic Biology 1999, 48:612-622.

84. Lewis P: A likelihood approach to estimating phylogeny from discrete morphological character data. Systematic Biology 2001, 50:913-925.

85. Goldberg E, Lancaster L, Ree R: Phylogenetic inference of reciprocal effects between geographic range evolution and diversification. Systematic Biology 2011, 60:451-465.

86. Maddison W, Midford P, Otto S: Estimating a binary character's effect on speciation and extinction. Systematic Biology 2007, 56:701-710.

87. Fitzjohn R, Maddison W, Otto S: Estimating trait-dependent speciation and extinction rates from incompletely resolved phylogenies. Systematic Biology 2009, 58:595-611.

88. Ree R, Moore B, Webb C, Donoghue M: A likelihood framework for inferring the evolution of geographic range on phylogenetic trees. Evolution 2005, 59:2299-2311.

89. Ree R, Smith S: Maximum likelihood inference of geographic range evolution by dispersal, local extinction, and cladogenesis. Systematic Biology 2008, 57:4-14.

90. Ree R, Sanmartın I: Prospects and challenges for parametric models in historical biogeographical inference. Journal of Biogeography 2009, 36:1211-1220.

91. Gradstein F, Ogg J, Smith A: Geologic time scale 2004 UK: Cambridge University Press; 2005.

92. Tamura K, Nei M, Kumar S: Prospects for inferring very large phylogenies by using the neighbor-joining method. Proceedings of the National Academy of Science of USA 2004, 101:11030-11035.

93. Tamura K, Dudley J, Nei M, Kumar S: MEGA4: Molecular Evolutionary Genetics Analysis (MEGA) software version 4.0. Molecular Biology and Evolution 2007, 24:1596-1599.

94. Harvey J, Goff L: A reassessment of species boundaries in Cystoseira and Halidrys (Phaeophyceae, Fucales) along the North American West coast. Journal of Phycology 2006, 42:707-720.

doi:10.1186/1471-2148-11-371

Cite this article as: Cánovas et al:: Driving south: a multi-gene phylogeny of the brown algal family Fucaceae reveals relationships and recent drivers of a marine radiation. BMC Evolutionary Biology 2011 11:371. 